\title{
KONTRIBUSI GHRM, GREEN INPUT, GREEN PROCESS DAN GREEN PRODUCT TERHADAP ECONOMIC PERFORMANCE
}

\author{
Sumiati ${ }^{1)}$, Romi Susanto ${ }^{2)}$ \\ ${ }^{1,2}$ Sekolah Tinggi Ilmu Ekonomi KBP, Padang, Indonesia \\ Email : sumiati@akbpstie.ac.id
}

\begin{abstract}
The contribution GHRM, green input, green process and green product has an impact on the economic performance and environmental sustainability. This study aims to look empirically at the effect of the GHRM, Green Process and Green Product to increase economic performance. The object of this research is that the center IKM in Sumatera Barat. Data analysis method used in this paper is regression analyss. Samples taken using purposive sampling. The results showed that the GHRM variable had significant and positive effects on the economic performace, green input had significant and positive effects on the economic performace, green proces had significant and positive effects on the economic performace, and green product had significant and positive effects on the economic performance.
\end{abstract}

Keywords: GHRM, green input, green process green product and economic performance

Abstrak Kontribusi GHRM, green input, green process dan green product memberikan dampak terhadap kinerja ekonomi dan keberlanjutan lingkungan. Penelitian ini bertujuan melihat secara empiris pengaruh GHRM, green input, green process dan green product untuk meningkatkan kinerja ekonomi. Objek penelitian dari penelitian ini adalah pusat IKM yang berada di Sumatera Barat. Metode analisis data penelitian ini menggunakan analisis regresi. Penarikan sampel menggunakan purposive sampling. Hasil penelitian menunjukkan bahwa variabel GHRM berpengaruh signifikan dan positif terhadap economic performance, green input berpengaruh positif dan signifikan terhadap economic performance, green process berpengaruh positif dan signifikan terhadap economic performance, dan green product berpengaruh positif dan signifikan terhadap economic performance.

Kata kunci : GHRM, green input, green process, green product dan economic performance

\section{A. PENDAHULUAN}

Ketidakseimbangan antara pertumbuhan industri dengan lingkungan telah membuat kerusakan di muka bumi. Global warning, Climate exchange merupakan contoh dari berbagai kerusakan yang terjadi saat ini. Pada umumnya pemilik usaha tidak menyadari dan hanya memusatkan untuk memproleh keuntungan yang setinggi-tingginya. Penelitian Agan; Fatih \& Borodin (2013) perusahaan baik itu berskala kecil, menengah dan besar telah berkontribusi atas masalah lingkungan berupa polusi, limbah gas, cair maupun padat. Huang (2013) menyatakan industri dihadapkan dengan tekanan-tekanan terhadap upaya penyelamatan lingkungan. Industri dituntut untuk melakukan perubahan dalam menjalankan aktivitas dan lebih peduli terhadap linkungan.

Oleh karena itu sebagai wujud dari kepedulian dunia terhadap lingkungan berbagai upaya penyelamatan telah dilakukan diantaranya Protokol Kyoto (Kyoto Protocol) pada tahun 1997. Ditambahkan oleh Yu-chen (2013) dampak industri terhadap lingkungan untuk mengatasinya organiasasi harus mulai menyadari dan mulai mempraktekkan aktivitas industri yang ramah lingkungan. Kritikan terhadap dunia industri tahun 1990an memunculkan konsep GHRM. Menurut Jackson (2014) GHRM bertujuan agar industri menyelamatkan dan memperbaiki lingkungan berdasar kepada sumber daya manusia.. Green Human Resource Management salah satu kunci dimana GHRM berperan aktif menciptakan komitmen pelaku industri mampu menciptakan produk yang ramah terhadap lingkungan. 
Laosirihongthong \& Tan (2013) mengajak dunia usaha dan masyarakat untuk mulai peduli dan berkontribusi lebih terhadap dunia usaha dan tidak membahayakan lingkungan, pemerintah dan organisasi di seluruh dunia berupaya untuk meminimalkan dampak terhadap lingkungan. Menurut data Balai Besar POM Sumbar tahun 2018 masih terdapat zat bahan berbahaya pada pangan sehari-hari seperti borax, formalin dan Rhodamin B.

IKM adalah industri berskala kecil dan menengah. Industri kecil dan menengah merupakan bagian integral dunia usaha nasional. Oleh karena itu pemerintah daerah saat ini sedang mengalakkan pengembangan industri ini. IKM berperan penting dalam pembangunan ekonomi nasional, mampu menyerap tenaga kerja dan meningkatkan PDB daerah.. Dari data Disperindag tahun 2018 IKM mengalami pertumbuhan dari tahun 2017 - 2018 sebesar 63,99\% dan kenaikan tenaga kerja sebesar 51,91\%, Adapun kendala atau rintangan IKM dalam menjalankan usahanya seperti pemasaran, teknologi, harga bahan baku yang sering berubah-ubah dan pengelolaan limbah. Penelitian Musa \& Chinniah (2016) industri kecil menengah ini selalu dihadapkan pada banyak masalah seperti kurangnya tenaga ahli, pengetahuan teknis, sedikit atau tidak adanya inovasi, kecilnya skala ekonomi, kesulitan dalam operasi metode tradisioanal serta banyak IKM kurang memperhatikan peningkatan keterampilan dan pengetahuan mereka.

Hal inilah yang menjadi motivasi peneliti untuk melakukan penelitian menginggat IKM adalah salah satu ekonomi rakyat Sumatera Barat diharapkan dengan pengelolaan yang baik mulai dari GHRM, green input, green process dan green product mampu meningkatkan kinerja ekonomi. Peneliti juga melihat secara empiris kesadaran pemilik IKM yang rendah terhadap lingkungan sehingga membawa dampak terhadap kerusakan lingkungan serta akibat lainnya yang ditimbulkan.

Pentingya penelitian ini karena masih rendahnya kesadaran pemilik IKM terhadap perlindungan lingkungan. Tujuan penelitian ini untuk menganalisis kontribusi GHRM, green input, green process green product terhadap economic performance IKM (industri kecil dan menengah) Pangan di Sumatera Barat. berdasarkan uraian tersebut maka dapat dirumuskan hipotesis pertama yaitu

\section{H1 : GHRM Berpengaruh Positif dan Signifikan Terhadap Economic Performance}

Pada prakteknya Green Human Resources Management (GHRM) merupakan manajemen sumber daya manusia (HRM) yang berkelanjutan bertujuan untuk meningkatkan komitmen karyawan terhadap kelestarian lingkungan, Masri \& Jaaron (2017): O'Connor, (2015). GHRM mengacu pada HRM terhadap lingkungan terkait dengan strategi perusahaan dan perilaku karyawan ramah lingkungan (Renwick; Redman; \& Maguire, 2012). Sedangkan Ahmad (2015) melihat dari sudut pandang aktivitas karyawan ramah lingkungan, identifikasi keberlanjutan dan lingkungan meliputi kegiatan: perekrutan karyawan ramah lingkungan, pengembangan manajemen kinerja ramah lingkungan, pelatihan karyawan ramah lingkungan dan kompensasi ramah lingkungan. Ada 2 konsep pendekatan yang menyokong pemberdayaan karyawan antara lain: 1) Pendekatan dari atas ke bawah (hubungan dan mekanisme), 2) bawah ke atas (psikologi) (Tariq et al., 2014). Oleh karena itu manajemen sumber daya memusatkan pada semua aktivitas yang terlibat dalam pengembangan, implementasi, pemeliharaan sistem berkelanjutan yang bertujuan untuk menciptakan karyawan ramah lingkungan (José; Jabbour; \& Almada, 2014).

\section{H2 : Green Input Berpengaruh Positif dan Signifikan Terhadap Economic Performance}

Input ramah lingkungan merupakan salah satu faktor produksi yang sangat penting. Menurut Samnani \& Singh (2013) penggunaan teknologi dalam proses produksi biokaltalis yang menghemat energi air dan mampu meningkatkan kualitas produk. Sedangkan Lin \& Xie (2015) industri yang melakukan efisiensi energi akan mengurangi penggunaan energi pada industri.

\section{H3 : Green Process Berpengaruh Positif dan Signifikan Terhadap Economic Performance}

Proses ramah lingkungan adalah proses produksi yang menggunakan sumber daya energi yang rendah seperti minyak, gas dan bahan-bahan yang dapat didaur ulang (Chiou; Kai; Lettice; \& Ho, 2011). Menurut Deif (2011) proses ramah lingkungan adalah proses yang menggambarkan 
cara baru berproduksi berdasarkan teknik dan strategi yang lebih efisien. Proses ramah lingkungan dapat juga dengan menggunakan pemecahan yang bersifat adiktif (Rennings; Ziegler; Ankele \& Hoffmann, 2006).

\section{H4 : Green Product Berpengaruh Positif dan Signifikan Terhadap Economic Performance}

Menurut Shen et al., (2019) produk ramah lingkungan signifikan dengan kualitas yang diinginkan dan keinginan konsumen untuk membeli kembali produk tersebut. Raharjo (2018) produk ramah lingkungan adalah produk yang diproduksi secara ramah lingkungan, bahan baku terbuat dari daur ulang. Selanjutnya Albino; Balice \& Dangelico (2009) dalam (Dost; Hussain; Bakhsh \& Ali, 2019) menyatakan bahwa produk ramah lingkungan adalah produk yang diproduksi yang memitigasi dampaknya terhadap lingkungan selama siklus produk hemat energi, rendah emisi, dan lebih ramah lingkungan. Studi terdahulu (Oliva et al., 2018) menyebutkan bahwa kinerja lingkungan bergantung pada kualitas produk ramah lingkungan, proses ramah lingkungan dan inovasi, penggabungan keberlanjutan ekologi dan pengembangan produk. Souza; Lamb \& Peretiatkos (2003) dari penelitiannya bahwa pelanggan cenderung menghormati pada industri yang ramah lingkungan. Lebih lanjut pengembangan produk ramah lingkungan dan pemasaran telah diperkenlakan pada yang sadar akan perlindungan lingkungan dan peraturan lingkungan (Chang \& Shiu 2013).

\section{B. METODE PENELITIAN \\ Data dan Sampel}

Populasi penelitian ini adalah sentra-sentra industri kecil dan menengah pangan (IKM) yang terletak di Sumatera Barat yaitu Kota Padang dan Payakumbuh sebesar 125 industri. Jenis data yang digunakan dalam penelitian adalah data primer dan sekunder. Teknik pengumpulan data yang digunakan adalah studi kepustakaan, kuesioner yang berisikan pertanyaan-pertanyaan (angket) mengenai GHRM, green input, green process, green product dan economic performance.

Penarikan sampel dalam penelitian ini diambil dengan menggunakan metode purposive sampling, yaitu suatu metode penarikan sampel dengan menetapkan kriteria khusus yang ditentukan oleh peneliti. Adapun kriteria-kriteria dalam pengambilan sampel tersebut antara lain:

1. IKM terdaftar pada Disperindag

2. Tenaga kerja yang digunakan maksimal 19 orang

3. IKM bergerak di bidang pangan

4. Nilai investasi kurang kurang dari 1 miliar

\section{Definisi Operasional Variabel}

Dalam penelitian ini, variabel yang digunakan terdiri dari dua macam, yaitu variabel bebas (independent variables) dan variabel terikat (dependent variables). Variabel bebas $\mathrm{X}$ dalam penelitian ini adalah GHRM, green input, green process dan green product. Sedangkan Y economic performance beperan sebagai variabel terikatnya. Definisi operasional masing-masing variabel dapat dilihat pada tabel berikut ini:

Tabel. 1

\begin{tabular}{c|l|c}
\hline Variabel & \multicolumn{1}{|c}{ Definisi Operasional Variabel } & Sumber \\
\hline $\begin{array}{c}\text { Economic } \\
\text { Performance }\end{array}$ & $\begin{array}{l}\text { Kinerja ekonomi adalah daya saing terkait dengan biya dari } \\
\text { hasil kegiatan social dan lingkungan. }\end{array}$ & $\begin{array}{l}\text { Annunziata, E., Pucci, T., } \\
\text { Frey, M., \& Zanni, L. } \\
\text { (2017) }\end{array}$ \\
\hline GHRM & $\begin{array}{l}\text { GHRM secara langsung bertanggung jawab dalam } \\
\text { menciptakan tenaga ramah lingkungan yang memahami, } \\
\text { menghargai, dan mempraktekkan inisiatif hijau dan } \\
\text { memelihara tujuan ramah lingkungan di seluruh proses. } \\
\text { HRM meliputi proses perekrutan, pelatihan, kompensasi, } \\
\text { pengembangan dan meningkatkan modal manusia dalam } \\
\text { perusahaan }\end{array}$ & Ahmad, S. (2015). \\
\hline Green input & Green input adalah bahan - bahan input yang digunakan & Barba, F. J., Gavahian, \\
\hline
\end{tabular}




\begin{tabular}{|c|c|c|}
\hline & $\begin{array}{l}\text { dalam indutri adalah bahan yang ramah lingkungan seperti } \\
\text { bahan baku, bahan pengganti yang tidak mengandung zat- } \\
\text { zat berbahaya dan bahan terbarukan. }\end{array}$ & $\begin{array}{l}\text { M., Es, I., Zhu, Z., } \\
\text { Chemat, F., Lorenzo, J. } \\
\text { M., \& Mousavi, A. } \\
\text { (2019). }\end{array}$ \\
\hline Green process & $\begin{array}{l}\text { Green process adalah proses produksi, bahan baku yang } \\
\text { digunakan tidak menyebabkan global warning, atau ramah } \\
\text { lingkungan. }\end{array}$ & Kusdi, R. (2018) \\
\hline Green product & $\begin{array}{l}\text { Green product adalah produk yang dihasilkan adalah } \\
\text { produk yang ramah lingkungan atau produk yang sadar } \\
\text { lingkungan, produk yang dirancang untuk mengurangi } \\
\text { konsumsi sumber daya alam yang dibutuhkan dan } \\
\text { meminimalkan dampak lingkungan yang merugikan selama } \\
\text { siklus hidup produk }\end{array}$ & Kusdi, R. (2018) \\
\hline
\end{tabular}

\section{Teknik Analisa Data}

Penelitian ini berbentuk pengujian hipotesis (hypothesis testing), tujuan pengujian ini untuk menguji pengaruh dari GHRM, green input, green process, green product terhadap economic performance. Pengolahan data pada penelitian ini menggunakan uji validitas, reliabilitas, uji asumsi klasik dan uji T. Metoda data dianalisis dengan menggunakan regresi berganda dengan menggunakan SPSS versi 16.

\section{HASIL DAN PEMBAHASAN}

Hasil pengolahan data tentang GHRM, green input, green process dan green product terhadap economic performance dilakukan uji instrumen, uji asumsi klasik dan regresi linear berganda serta uji t, untuk selanjutnya dapat dilihat sebagai berikut:

\section{Uji Instrumen Penelitian \\ Uji Validitas}

Untuk menilai kevalidan masing-masing butir pertanyaan dapat dilihat dari nilai corrected Item-Total Correlation masing-masing butir pertanyaan dengan melalui pengolahan menggunakan SPSS. Suatu butir pernyataan dikatakan valid jika nilai dari corrected item-Total Correlation $>$ 0,300 . Pengujian validitas selengkapnya dapat dilihat pada tabel berikut:

\section{a. Hasil Uji Validitas Variabel GHRM}

\section{Tabel 2}

Hasil Uji Validitas Variabel GHRM

\begin{tabular}{lrrrr}
\hline \multicolumn{5}{c}{ Item-Total Statistics } \\
\hline & $\begin{array}{c}\text { Scale Mean if } \\
\text { Item Deleted }\end{array}$ & $\begin{array}{c}\text { Scale Variance } \\
\text { if Item Deleted }\end{array}$ & $\begin{array}{c}\text { Corrected } \\
\text { Item-Total } \\
\text { Correlation }\end{array}$ & $\begin{array}{c}\text { Cronbach's } \\
\text { Alpha if Item } \\
\text { Deleted }\end{array}$ \\
\hline X1.1 & 16,83 & 4,318 &, 489 &, 843 \\
X1.2 & 16,82 & 3,533 &, 673 &, 797 \\
X1.3 & 16,72 & 3,639 &, 696 &, 789 \\
X1.4 & 16,69 & 3,765 &, 696 &, 790 \\
X1.5 & 16,78 & 3,885 &, 656 &, 801 \\
\hline
\end{tabular}

Berdasarkan dari Tabel 2 dapat dilihat dari hasil pengolahan data, bahwa dari 5 item pertanyaan memiliki nilai corrected item total correlation antara $0,489 \mathrm{~s} / \mathrm{d} 0,696$ atau dengan kata lain bahwa 5 item pertanyaan yang digunakan dalam mengukur variabel GHRM memiliki nilai corrected item total correlation lebih besar dari nilai kritis yaitu 0,300. Dengan demikian dapat disimpulkan bahwa 5 item pertanyaan tersebut adalah valid.

\section{b. Hasil Uji Validitas Variabel Green Input}


Tabel 3

Hasil Uji Validitas Variabel Green Input

\begin{tabular}{lrrrr}
\hline \multicolumn{5}{c}{ Item-Total Statistics } \\
\hline & $\begin{array}{c}\text { Scale Mean if } \\
\text { Item Deleted }\end{array}$ & $\begin{array}{c}\text { Scale Variance } \\
\text { if Item Deleted }\end{array}$ & $\begin{array}{c}\text { Corrected } \\
\text { Item-Total } \\
\text { Correlation }\end{array}$ & $\begin{array}{c}\text { Cronbach's } \\
\text { Alpha if Item } \\
\text { Deleted }\end{array}$ \\
\hline X2.1 & 16,70 & 4,584 &, 599 &, 816 \\
X2.2 & 16,69 & 3,894 &, 714 &, 782 \\
X2.3 & 16,80 & 3,710 &, 720 &, 780 \\
X2.4 & 16,70 & 3,891 &, 703 &, 785 \\
X2.5 & 16,51 & 4,768 &, 472 &, 845 \\
\hline
\end{tabular}

Berdasarkan dari Tabel 3 dapat dilihat dari hasil pengolahan data, bahwa dari 5 item pertanyaan memiliki nilai corrected item total correlation antara $0,472 \mathrm{~s} / \mathrm{d} 0,720$ atau dengan kata lain bahwa 5 item pertanyaan yang digunakan dalam mengukur variabel green input memiliki nilai corrected item total correlation lebih besar dari nilai kritis yaitu 0,300. Dengan demikian dapat disimpulkan bahwa 5 item pertanyaan tersebut adalah valid.

c. Hasil Uji Validitas Variabel Green Process

Tabel 4

Hasil Uji Validitas Variabel Green Process

\begin{tabular}{lrrrr}
\hline \multicolumn{5}{c}{ Item-Total Statistics } \\
\hline & $\begin{array}{c}\text { Scale Mean if } \\
\text { Item Deleted }\end{array}$ & $\begin{array}{c}\text { Scale Variance } \\
\text { if Item Deleted }\end{array}$ & $\begin{array}{c}\text { Corrected } \\
\text { Item-Total } \\
\text { Correlation }\end{array}$ & $\begin{array}{c}\text { Cronbach's } \\
\text { Alpha if Item } \\
\text { Deleted }\end{array}$ \\
\hline X3.1 & 16,70 & 4,584 &, 599 &, 816 \\
X3.2 & 16,69 & 3,894 &, 623 &, 782 \\
X3.3 & 16,80 & 3,710 &, 753 &, 780 \\
X3.4 & 16,70 & 3,891 &, 703 &, 785 \\
X3.5 & 16,51 & 4,768 &, 452 &, 845 \\
\hline
\end{tabular}

Berdasarkan dari Tabel 4 dapat dilihat dari hasil pengolahan data, bahwa dari 5 item pertanyaan memiliki nilai corrected item total correlation antara $0,452 \mathrm{~s} / \mathrm{d} 0,753$ atau dengan kata lain bahwa 5 item pertanyaan yang digunakan dalam mengukur variabel green process memiliki nilai corrected item total correlation lebih besar dari nilai kritis yaitu 0,300. Dengan demikian dapat disimpulkan bahwa 5 item pertanyaan tersebut adalah valid.

d. Hasil Uji Validitas Variabel Green Product

Tabel 5

Hasil Uji Validitas Variabel Green Product

\begin{tabular}{lrrrr}
\hline \multicolumn{5}{c}{ Item-Total Statistics } \\
\hline & $\begin{array}{c}\text { Corrected } \\
\text { Item Deleted }\end{array}$ & $\begin{array}{c}\text { Scale Variance } \\
\text { if Item Deleted }\end{array}$ & $\begin{array}{c}\text { Cronbach's } \\
\text { Item-Total } \\
\text { Correlation }\end{array}$ & $\begin{array}{c}\text { Alpha if Item } \\
\text { Deleted }\end{array}$ \\
\hline X4.1 & 17,12 & 3,155 &, 529 &, 808 \\
X4.2 & 16,83 & 4,447 &, 586 &, 742 \\
X4.3 & 16,78 & 4,256 &, 644 &, 724 \\
X4.4 & 16,73 & 4,425 &, 626 &, 734 \\
X4.5 & 16,80 & 4,210 &, 616 &, 730 \\
\hline
\end{tabular}

Berdasarkan dari Tabel 5 dapat dilihat dari hasil pengolahan data, bahwa dari 5 item pertanyaan memiliki nilai corrected item total correlation antara $0,529 \mathrm{~s} / \mathrm{d} 0,644$ atau dengan kata lain bahwa 5 item pertanyaan yang digunakan dalam mengukur variabel green product memiliki 
nilai corrected item total correlation lebih besar dari nilai kritis yaitu 0,300. Dengan demikian dapat disimpulkan bahwa 5 item pertanyaan tersebut adalah valid.

\section{e. Hasil Uji Validitas Variabel Economic Performance}

Tabel 6

Hasil Uji Validitas Variabel Economic Performance

\begin{tabular}{lrrrr}
\hline \multicolumn{5}{c}{ Item-Total Statistics } \\
\hline & $\begin{array}{c}\text { Corrected } \\
\text { Scale Mean if } \\
\text { Item Deleted }\end{array}$ & $\begin{array}{c}\text { Scale Variance } \\
\text { if Item Deleted }\end{array}$ & $\begin{array}{c}\text { Item-Total } \\
\text { Correlation }\end{array}$ & $\begin{array}{c}\text { Cronbach's Alpha } \\
\text { if Item Deleted }\end{array}$ \\
\hline Y1 & 17,07 & 3,342 &, 624 &, 772 \\
Y2 & 16,82 & 3,587 &, 671 &, 759 \\
Y3 & 16,82 & 3,732 &, 615 &, 775 \\
Y4 & 16,95 & 3,627 &, 522 &, 804 \\
Y5 & 16,82 & 3,678 &, 603 &, 778 \\
\hline
\end{tabular}

Berdasarkan dari Tabel 6 dapat dilihat dari hasil pengolahan data, bahwa dari 5 item pertanyaan memiliki nilai corrected item total correlation antara $0,522 \mathrm{~s} / \mathrm{d} 0,671$ atau dengan kata lain bahwa 5 item pertanyaan yang digunakan dalam mengukur variabel economic performance memiliki nilai corrected item total correlation lebih besar dari nilai kritis yaitu 0,300. Dengan demikian dapat disimpulkan bahwa 5 item pertanyaan tersebut adalah valid.

\section{Uji Reliabilitas}

Uji reliabilitas adalah alat untuk mengukur suatu kuesioner yang merupakan indikator dari suatu variabel atau konstruk. Secara umum uji reliabilitas didefenisikan sebagai rangkaian uji lanjutan untuk menilai kehandalan dari item-item pertanyaan yang valid yang dilihat dari nilai cronbach alpha yang dihasilkan $>0,60$.

\section{Tabel 7}

Uji Reabilitas Variabel Penelitian

\begin{tabular}{lccc}
\hline \multicolumn{4}{c}{ Item-Total Statistics } \\
\hline \multicolumn{1}{c}{ Variable } & $\begin{array}{c}\text { Cronbach's } \\
\text { alpha }\end{array}$ & Nilai Kritis & Kesimpulan \\
\hline GHRM & 0,838 & 0.60 & Reliabel \\
Green Inpu & 0,837 & 0.60 & Reliabel \\
Green Process & 0,837 & 0,60 & Reliabel \\
Green Product & 0,784 & 0,60 & Reliabel \\
Ekonomic Perormance & 0,814 & 0,60 & Reliabel \\
\hline
\end{tabular}

Berdasarkan table 7 dapat dilihat dari hasil pengolahan data bahwa nilai cronbac'h alpha untuk GHRM, green input, green process, green product dan economic performance $>0,60$. Maka dapat disimpulkan bahwa butir pertanyaan yang valid tersebut handal.

\section{Uji Asumsi Klasik \\ Uji Normalitas}

Uji normalitas berguna untuk menguji apakah dalam model regresi, variabel dependen dan variabel independenmmemiliki berdistribusi normal atau tidak. Uji normalitas pada penelitian ini menggunakan uji One-Sampel Kormogorov-Smirmov.

\section{Tabel 8}

Hasil Uji Normalitas 


\begin{tabular}{llr}
\hline N & & 125 \\
Normal Parameters ${ }^{\mathrm{a}, \mathrm{b}}$ & Mean &, 0000000 \\
& Std. Deviation &, 98373875 \\
Most Extreme & Absolute &, 079 \\
Differences & Positive &, 041 \\
& Negative &,- 079 \\
Test Statistic & &, 079 \\
Asymp. Sig. (2-tailed) & &, $054^{\mathrm{c}}$ \\
\hline
\end{tabular}

Terlihat bahwa nilai Asymp. Sig. (2-tailed) dari hasil pengujian normalitas adalah sebesar 0.054. Nilai ini lebih besar dari 0.05. Hal ini menunjukkan bahwa nilai residual dari model regresi telah terdistribusi secara normal.

\section{Uji Multikolinearitas}

Uji Multikolinieritas berguna untuk menguji apakah model regresi ditemukan adanya korelasi antar variabel independen. Cara mengetahui ada tidaknya penyimpangan uji multikolinieritas adalah dengan melihat nilai Tolerance dan VIF masing-masing variabel independen, jika nilai Tolerance $>0.10$ dan nilai VIF $<10$, maka data bebas dari gejala multikolinearitas.

\section{Tabel 9}

\begin{tabular}{|c|c|c|c|c|c|c|c|}
\hline \multicolumn{8}{|c|}{ Hasil Uji Multikolinearitas } \\
\hline \multicolumn{8}{|c|}{ Coefficients ${ }^{\mathrm{a}}$} \\
\hline \multirow[b]{3}{*}{ Model } & \multicolumn{2}{|c|}{$\begin{array}{l}\text { Unstandardized } \\
\text { Coefficients }\end{array}$} & $\begin{array}{l}\text { Standardized } \\
\text { Coefficients }\end{array}$ & \multirow[b]{3}{*}{$\mathrm{t}$} & \multirow[b]{3}{*}{ Sig. } & \multicolumn{2}{|c|}{$\begin{array}{c}\text { Collinearity } \\
\text { Statistics }\end{array}$} \\
\hline & & & & & & Toleranc & \\
\hline & B & Std. Error & Beta & & & $\mathrm{e}$ & VIF \\
\hline 1 (Constant) & 5,681 & 1,781 & & 3,189 & 002 & & \\
\hline GHRM &, 066 & 033 &, 130 & 2,006 & 047 & ,966 & 1,035 \\
\hline Green Input & 006 & 060 &, 006 & 097 & ,923 & 961 & 1,041 \\
\hline Green Process & 241 & 076 & 294 & 3,172 & 002 & ,476 & 2,101 \\
\hline Green Product & 419 & 085 & ,446 & 4,927 &, 000 & ,499 & 2,003 \\
\hline
\end{tabular}

Tabel 9 menunjukkan bahwa secara keseluruhan tidak ada variabel independen yang memiliki nilai Tolerance kurang dari 0.10 dan nilai VIF besar dari 10. Dapat disimpulkan bahwa masing-masing variabel independen bebas dari gejala multikolinearitas.

\section{Uji Heteroskedastisitas}

Uji heteroskedastisitas bertujuan untuk menguji dalam model regresi terjadi ketidaksamaan varians dari residual satu pengamatan ke pengamatan yang lain. Cara untuk mengetahui terjadi heteroskedastisitas atau tidak yaitu dengan melakukan uji Glejser.

Tabel 10

Hasil Uji Heteroskedastisitas

\begin{tabular}{|c|c|c|c|c|c|c|}
\hline \multicolumn{7}{|c|}{ Coefficients $^{\mathbf{a}}$} \\
\hline \multirow[b]{2}{*}{ Model } & & \multicolumn{2}{|c|}{ Unstandardized Coefficients } & $\begin{array}{l}\text { Standardized } \\
\text { Coefficients }\end{array}$ & \multirow[b]{2}{*}{$\mathrm{t}$} & \multirow[b]{2}{*}{ Sig. } \\
\hline & & $\mathrm{B}$ & Std. Error & Beta & & \\
\hline 1 & (Constant) &,- 035 & 1,113 & &,- 032 & ,975 \\
\hline & GHRM &,- 014 &, 022 &,- 058 &,- 648 &, 518 \\
\hline & Green Input &,- 049 & 043 &,- 111 & $-1,149$ & 253 \\
\hline & Green Process & ,074 & ,040 & ,189 & 1,835 & ,069 \\
\hline Dene & $\begin{array}{l}\text { Green Product } \\
\text {. }\end{array}$ & FS? & ,045 & ,115 & 1,142 & 256 \\
\hline
\end{tabular}


Berdasarkan Tabel 10 terlihat bahwa masing-masing variabel independen memiliki nilai signifikansi yang lebih besar dari 0.05 . Hal ini menunjukkan bahwa tidak terjadi gejala heteroskedastisitas terhadap data yang digunakan dalam penelitian ini.

\section{Hasil Model Regresi}

Pengujian ini bertujuan untuk mengetahui hubungan signifikan dari variable GHRM, green input, green process, green product terhadap economic performance. Untuk melihat apakah hipotesis diterima atau ditolak digunakan analisis regresi berganda dan hasil uji-t. Tingkat signifikansi yang digunakan adalah 5\%. Model statistik yang diestimasi adalah model terbaik dan terbebas dari gejala asumsi klasik. Hasil pengujian dapat dilihat pada Tabel berikut:

\section{Tabel 11 \\ Hasil Uji Regresi Berganda}

\begin{tabular}{|c|c|c|c|c|c|c|}
\hline \multicolumn{7}{|c|}{ Coefficients $^{\mathrm{a}}$} \\
\hline \multirow[b]{2}{*}{ Model } & & \multicolumn{2}{|c|}{ Unstandardized Coefficients } & $\begin{array}{l}\text { Standardized } \\
\text { Coefficients }\end{array}$ & \multirow[b]{2}{*}{$\mathrm{t}$} & \multirow[b]{2}{*}{ Sig. } \\
\hline & & $\mathrm{B}$ & Std. Error & Beta & & \\
\hline \multirow[t]{5}{*}{1} & (Constant) & 2,883 & 1,905 & & 1,513 & ,133 \\
\hline & GHRM &, 082 &, 033 & 164 & 2,504 & 014 \\
\hline & Green Input & ,130 & ,058 & ,151 & 2,250 & 026 \\
\hline & Green Process & 187 & ,078 & ,228 & 2,412 & 017 \\
\hline & Green Product & , 466 & ,086 & 496 & 5,426 & 000 \\
\hline \multicolumn{7}{|c|}{ a. Dependent Variable: Ekonomi Perormance } \\
\hline
\end{tabular}

Hasil estimasi model regresi seperti terlihat pada table 11, dimana konstanta sebesar 0.2883 artinya jika diasumsikan variabel independen (GHRM, green input, green process, green product) bernilai 0 (nol), maka nilai variabel dependen (economic performance) sebesar 0.2883. Variabel GHRM (X1) mempunyai nilai 0.082 artinya bahwa setiap terjadi kenaikan variabel GHRM sebesar 1 satuan, maka economic performance $(\mathrm{Y})$ akan mengalami peningkatan sebesar 0.082. Variabel green input (X2) mempunyai nilai 0.130 artinya bahwa setiap terjadi kenaikan variabel green input sebesar 1 satuan, maka economic performance (Y) akan mengalami peningkatan sebesar 0.10. Dengan asumsi variabel lain tetap. variabel green process (X3) mempunyai nilai 0.187 artinya bahwa setiap terjadi kenaikan variabel green process sebesar 1 satuan, maka economic performance (Y) akan mengalami peningkatan sebesar 0.187. Sedangkan variabel lain tetap. variabel green product (X4) mempunyai nilai 0.466 artinya bahwa setiap terjadi kenaikan variabel green product sebesar 1 satuan, maka economic performance (Y) akan mengalami peningkatan sebesar 0.466 .

Hasil tingkat signfikansi dari hasil penelitian ini membuktikan bahwa variabel GHRM (X1) memiliki nilai t hitung sebesar 2.504 dengan nilai probabilitas signifikansi sebesar 0.014 yang lebih kecil dari 0.05. Dengan demikian dapat disimpulkan bahwa H1 diterima. Berarti variabel green input berpengaruh signifikan terhadap economic performance. Variabel green input (X2) juga menunjukkan hasil yang signifikan dengan nilai t hitung sebesar 2.250 pada tingkat signifikansi 0.026. Nilai signifikansi 0.026 lebih kecil dari 0.05. Dengan demikian, H2 juga diterima. Hal ini berarti green input berpengaruh signifikan terhadap economic performance. Kemudian variabel green process juga menunjukkan hasil yang signifikan dengan nilai t hitung sebesar 2.412 pada tingkat signifikansi 0.017. Nilai signifikansi 0.017 lebih kecil dari 0.05. Dengan demikian, H3 juga diterima. Hal ini berarti green input berpengaruh signifikan terhadap economic performance. Hasil uji statistik juga konsisten terhadap variabel green product (X4). Dimana nilai t hitung dari variabel green product sebesar 5.426 dengan tingkat signifikansi yang lebih kecil dari 
0.05, yaitu 0.000. Dengan demikian dapat disimpulkan bahwa $\mathrm{H} 4$ diterima. Berarti variabel green product berpengaruh signifikan terhadap economic performance.

\section{PEMBAHASAN \\ Pengaruh GHRM Terhadap Economic Performance}

Berdasarkan hasil analisis menunjukkan GHRM berpengaruh signifikan terhadap kinerja ekonomi. Zaid et al., (2018) menjelaskan bahwa GHRM berpengaruh terhadap kinerja ekonomi. Kelayakan ekonomi menjadi faktor kunci untuk menentukan suatu produk. Pemilik harus memperhatikan biaya yang akan dikeluarkan untuk investasi atau modifikasi alat atau kompensasi berupa penghematan. Mehta and Chugan (2015) menyebutkan perbaikan penjualan dan penurunan biaya adalah suatu usaha untuk mempromosikan perusahaan ramah lingkungan. Disamping itu pendekatan bisnis strategi yang inovatif terbukti jauh lebih menguntungkan bagi perusahaan daripada mengandalkan hal-hal baru dalam produksi dan perusahaan inovatif dapat berkontribusi memitigasi penurunan ekonomi global dengan mendorong pertumbuhan ekonomi yang berkelanjutan. Hal ini sejalan dengan penelitian Lebih lanjut Tom (2015) menjelaskan kinerja ekonomi adalah kemampuan industri untuk menciptakan inovasi.

\section{Pengaruh Green Input Terhadap Economic Performance}

Berdasarkan hasil analisis menunjukkan input ramah lingkungan berpengaruh signifikan terhadap kinerja ekonomi pada IKM Sumbar. Temuan ini menunjukkan input ramah lingkungan akan mampu menaikkan kinerja ekonomi karena beragam teknik seperti input, energi terbarukan yang mampu mengurangi biaya produksi.

Disamping itu terdapat strategi pencegahan pencemaranyang dapat mengurangi biaya investasi seperti biaya pengolahan, pembuangan limbah atau perbaikan lingkungan serta mengurangi biaya-biaya lainnya. Penggunaan input ramah lingkungan juga akan mampu memelihara dan memperkuat pertumbuhan ekonomi jangka panjang melalui konservasi sumber daya, bahan baku dan energi. Industri juga akan mendorong pengembangan teknologi baru yang lebih efisien dan akrab lingkungan. Input ramah lingkungan juga dapat memperkuat daya saing produk di pasar domestik dan ineternasional otomatis akan menaikkan kinerja ekonomi. Hal ini diperkuat dengan penelitian Raharjo (2018) bahwa input ramah lingkungan akan menghasilkan keuntungan baik jangka pendek maupun jangka panjang termasuk penghematan biaya, meningkatkan citra perusahaan, serta meningkatkan hubungan dengan masyarakat setempat.

\section{Pengaruh Green Process Terhadap Economic Performance}

Berdasarkan hasil analisis menunjukkan bahwa proses ramah lingkungan berpengaruh signifikan terhadap kinerja ekonomi. Hal ini dipertegas oleh Huo et al., (2019) yang menyatakan bahwa proses ramah lingkungan berpengaruh terhadap kinerja ekonomi. Program penerapan proses ramah lingkungan harus direncanakan dengan baik melalui komitmen pemilik industri melalui tindakan minimasi seperti minimasi limbah.

Hal ini sejalan dengan penelitian Weng et al., (2015) menyebutkan proses ramah lingkungan tidak hanya mengurangi dampak lingkungan juga meningkatkan kinerja ekonomi. Penerapan proses ramah lingkungan dapat dilakukan dengan berbagai kajian antara lain, biaya pengelolaan, pembuangan limbah, bahan baku, produk, utilitas, biaya operasi, pemeliharaan dan laporan keuangan. Lebih lanjut dalam penelitian Klassen (2000) melihat dari perspektif NRBV, proses eksternal ramah lingkungan mewakili kemampuan pelayanan produk. Perusahaan yang menyerap pengetahuan lingkungan dan mempunyai pengalaman mampu melindungi rantai pasokan dengan mengadopsi proses ramah lingkungan. Berkembang sebagai sumber daya dan kemampuan unik yang meningkatkan tidak hanya kinerja lingkungan juga kinerja ekonomi dan kinerja sosial.

\section{Pengaruh Green Product Terhadap Economic Performance}

Berdasarkan hasil analisis menunjukkan produk ramah lingkungan berpengaruh positif dan signifikan terhadap kinerja ekonomi. Temuan ini menunjukkan bahwa produk ramah lingkungan 
mampu menaikkan kinerja ekonomi. Hal ini didukung oleh penelitian Yi-Chun Huang (2010) menyatakan produk ramah lingkungan berpengaruh terhadap kinerja ekonomi. Akibat gaya hidup masyarakat yang saat ini mulai menyadari pentingnya menjaga kesehatan, masyarakat mulai beralih menggunakan produk sehat dan ramah lingkungan. Hal ini juga tertuang pada standar ISO 14001 yang mendukung perlindungan lingkungan dan pencegahan pencemaran yang seimbang dengan kebutuhan sosio-ekonomis. Pengembangan produk ramah lingkungan diharapkan akan mampu menekan biaya produksi.

\section{SIMPULAN}

Penelitian yang dilakukan pada 125 responden yang berada di sekitar area Padang dan Payakumbuh yang memberikan responnya terhadap economic performance dengan menggunakan uji instrumen, uji asumsi klasik dan regresi linear berganda serta uji t. Hasil penelitian menunjukkan bahwa berdasarkan hipotesis bahwa variable GHRM menpengaruhi secara signfikan terhadap economic performance, kemudian diikuti variable green input, variable green process dan variabel green product berpengaruh secara signifikan terhadap economic performance dimana masing-masing variabel memiliki nilai t-hitung lebih besar dari nilai t-tabel dengan nilai probilitas kecil dari nilai alpha.

\section{E. UCAPAN TERIMA KASIH}

Ucapan terima kasih peneliti sampaikan kepada Direktorat Jenderal Penguatan Riset dan Pengembangan Kementerian Riset, Teknologi dan Pendidikan Tinggi (DRPM Ristekdikti) yang telah memberikan dana, sehingga peneliti dapat melakukan penelitian ini dengan lancar. Terima kasih juga dihaturkan kepada Dinas Perindustrian dan Perdagangan Sumbar atas kesediaannya untuk memberikan data-data yang peneliti butuhkan. Penghargaan dan terima kasih juga peneliti ucapkan kepada Sekolah Tinggi Ilmu "KBP" yang telah memberikan dukungan, izin dan tugas kepada peneliti guna melakukan penelitian dan penulisan jurnal ini.

\section{F. DAFTAR PUSTAKA}

1. Agan, Y., Fatih, M., \& Borodin, A. (2013). Drivers of Environmental Processes and Their Impact On Performance : a study of Turkish SMEs. Journal of Cleaner Production, 51, 23-33. https://doi.org/10.1016/j.jclepro.2012.12.043

2. Albino, V., Balice, A., \& Dangelico, R. M. (2009). Environmental Strategies and Green Product Development : an Overview on Sustainability Driven Companies. Wiley Interscience, 96, 83-96.

3. Annunziata, E., Pucci, T., Frey, M., \& Zanni, L. (2017). The Role of Organizational Capabilities In Attaining Corporate Sustainability Practices and Economic Performance : Evidence from Italian Wine Industry. Journal of Cleaner Production. https://doi.org/10.1016/2017.10.035

4. Ahmad, S. (2015). Green Human Resource Management: Policies and practices. Cogent Business \& Management, 25(1), 1-13. https://doi.org/10.1080/23311975.2015.1030817

5. Barba, F. J., Gavahian, M., Es, I., Zhu, Z., Chemat, F., Lorenzo, J. M., \& Mousavi, A. (2019). Solar Radiation As A Prospective Energy Source for Green and Economic Processes In The Food Industry : From Waste Biomass Valorization To Dehydration, Cooking and Baking. Journal of Cleaner Production 220, 1121-1130. https://doi.org/10.1016/j.jclepro.2019.02.175

6. Chiou, T., Kai, H., Lettice, F., \& Ho, S. (2011). The Influence of Greening The Suppliers and Green Innovation on Environmental Performance and Competitive Advantage in Taiwan. Transportation Research Part E, 47(6), 822-836. https://doi.org/10.1016/j.tre.2011.05.016

7. Deif, A. M. (2011). A System Model For Green Manufacturing. Journal of Cleaner Production, 19(14), 1553-1559. https://doi.org/10.1016/j.jclepro.2011.05.022

8. Hair et al. (2014). Multivariate Data Analysis Joseph F. Hair Jr. William C . Black Seventh Edition.

9. Hosain, S., \& Rahman, S. (2016). Green Human Resource Management: A Theoretical 
Overview, 18(6), 54-59. https://doi.org/10.9790/487X-1806035459

10. Huang, F.-H. K. and C.-L. (2013). Assessing The Green Value Chain to Improve Environmental Performance Evidence From Taiwan's Manufacturing Industry Fan-Hua. Intern. Journal of Development Issues, Vol. 11 Is.

11. Kusdi, R. (2018). and Medium Enterprises. The Role of Green Management in Creating Sustainability Performance on The Small and Medium Enterprises. Management of Environmental Guality:An International Journal. https://doi.org/10.1108/MEQ-03-2018-0053

12. Klassen, R. D. (2000). Just in Time Manufacturing and Pollution Prevention Generate Mutual Benefits in the Furniture Industry, (November 2015).

13. Lin, B., \& Xie, X. (2015b). Factor Substitution and Rebound Effect in China's Food Industry. Energy Conversion and Management, 105, 20-29. https://doi.org/10.1016/j.enconman.2015.07.039

14. Laosirihongthong, T., \& Tan, K. C. (2013). Green Supply Chain Management Practices and Performance. https://doi.org/10.1108/IMDS-04-2013-0164

15. Musa, H., \& Chinniah, M. (2016). Malaysian SMEs Development : Future and Challenges on Going. Procedia - Social and Behavioral Sciences, 224(August 2015), 254-262. https://doi.org/10.1016/j.sbspro.2016.05.457

16. Oliva, F. L., Semensato, B. I., Prioste, D. B., Jacques, E., Winandy, L., Bution, J. L., Fabiani, S. (2018). Innovation in The Main Brazilian Business Sectors: Characteristics, Types and Comparison of Innovation. https://doi.org/10.1108/JKM-03-2018-0159

17. O'Connor, G. R. A. (2015). Government Policy Implications of Intellectual Capital: an Australian Manufacturing Case Study. Journal of Intellectual Capital.

18. Renwick, D. W. S., Redman, T., \& Maguire, S. (2012). Green Human Resource Management : A Review and Research Agenda. International Journal of Management Reviews. https://doi.org/10.1111/j.1468-2370.2011.00328.

19. Shen, B., Lin, S., Hooi, B., Loong, H., Pei, W., Ng, Q., Rambli, J. (2019). An Outlook of Malaysian Biomass Industry Commercialisation: Perspectives and Challenges. Renewable $\begin{array}{lllll}\text { and Sustainable Energy } & \text { Reviews, } 113 \quad \text { (July), } & 109277 .\end{array}$ https://doi.org/10.1016/j.rser.2019.109277

20. Schuler, R., Jackson, S. E., (2014). Human Resource Management and Organizational Effectiveness : Yesterday and Today. https://doi.org/10.1108/JOEPP-01-2014-0003

21. Singh, G., \& Kumar, S. (2019). International Journal of Biological Macromolecules Utility of Laccase In Pulp and Paper Industry: A progressive Step Towards The Green Technology. International Journal of Biological Macromolecules, 134, 1070-1084. https://doi.org/10.1016/j.ijbiomac.2019.05.168

22. Souza, C. D., Lamb, P., \& Peretiatkos, R. (2003). Green Products and corporate Strategy: An Empirical Investigation. https://doi.org/10.1108/17465680610669825

23. Tariq, S., Ali, F., \& Ahmad, M. S. (2014). Green Employee Empowerment: A Systematic Literature Review on State-Of-Art In Green Human Resource Management. https://doi.org/10.1007/s11135-014-0146-0

24. Tom, N. (2015). Corporate Sustainability And Economic Performance In Small and Medium Sized Enterprises, 108. https://doi.org/10.1016/j.jclepro.2015.08.106

25. Weng, H. R., Chen, J., \& Chen, P. (2015). Effects of Green Innovation on Environmental and Corporate Performance: A Stakeholder Perspective, 4997-5026. https://doi.org/10.3390/su7054997

26. Xie, X., Huo, J., \& Zou, H. (2019). Green Process Innovation, Green Product Innovation, and Corporate Financial Performance: A content analysis method is. Journal of Business Research, (January), 1-10. https://doi.org/10.1016/j.jbusres.2019.01.010

27. Yu-chen, W. S.-I. and W. (2013). The Influence of Enterprises' Green Management Awareness On Green Management Strategy and Organizational Performance..

28. Zaid, A. A., Jaaron, A. A. M., \& Bon, A. T. (2018). The Impact of Green Human Resource management and green supply chain management practices on sustainable performance: An 
Menara Ekonomi, ISSN : 2407-8565; E-ISSN: 2579-5295

Volume VII No. 2 - Oktober 2021

empirical study. Journal of Cleaner Production. https://doi.org/10.1016/j.jclepro.2018.09.062 